Shaw DR and Allen TFH (2017) Studying innovation ecosystems using ecology theory Technological Forecasting and Social Change. Special issue on innovation ecosystems.

\title{
Studying innovation ecosystems using ecology theory
}

Brief running title: Innovation ecosystems using ecology theory

Duncan R. Shaw ${ }^{1}$ (corresponding author, +44 (0) 115 8467756.) and Tim Allen².

Email: duncan.shaw@nottingham.ac.uk, tfallen@wisc.edu

${ }^{1}$ Nottingham University Business School, Jubilee Campus, Nottingham, NG8 1BB, UK.

${ }^{2}$ University of Wisconsin, Gaylord Nelson Institute of Environmental Studies, Madison WI USA

\begin{abstract}
This paper proposes a set of perspectives for studying innovation ecosystems that are based on ecological research. Our perspectives are based on fundamental similarities between natural and business systems. We suggest that innovation ecosystems can be defined as pathways of interlinked business models. Pathways are characterised by the flows they convey not the types of business model that support the flows. These pathways convey material and informational resources, as well as value. Like the nutrient and energy pathways in natural ecosystems. Pathways help to recycle scarce resources such as customer attention and customer-derived information. Business model descriptions are similar to an organism's genome in that they describe limitations on sensing, acting and understanding. We conceptualise this as the 'umwelt'; the self-world. These limitations have implications for how firms and customers interact with customers. They have other implications for how firms interact with each other in business model communities and how they accommodate each other.
\end{abstract}

We illustrate and test these ecological perspectives using a case study of a healthcare smartphone app's ecosystem. We find that our perspectives can be used as novel methods of studying interactions between business models; or to study ecosystem building.

Keywords: innovation ecosystems; ecology theory; digital ecosystems, business models; value creation systems; complementary umwelts.

\section{Introduction}

The 'Internet of Things' (IoT) is based on sensors and a Wi-Fi connection to the cloud that are cheap enough for almost any product to be connected to the Internet. It can then share data with other Things (Porter and Heppelmann, 2014; Porter and Heppelmann, 2015). Even wooden pallets have been able to share location data when Radio Frequency ID chips are stuck to them. This is what originally enabled UPS to give their customers a service that told them where their packages were and how long until it was delivered (UPS, 2005). Modern mobile phones combine location, movement and other sensors with powerful information processing capabilities and several different types of wireless connectivity.

Terms like ‘digital ecosystem' are commonly used to acknowledge the interconnected nature of new digital industries. One example of this is the idea of a 'smart city' which combines elements of the Internet of Things but with a focus on particular urban spaces and the people and organisations that live and work in them (Chourabi et al., 2012). However, it is far from clear how to construct a smart city or how to make a city smart because it has never been done before. Smart cities themselves are emergent phenomena; like the Big Data and IoT technologies that enable smart cities. Emergents that have not been seen before are impossible to predict. The component hardware, software and mathematical tools of Big Data are being invented, combined and recombined in different ways and it is by no means obvious how this will turn out. The same complex forecasting problems also apply to IoT products. But new products and services can be deployed differently with different business models (Chesbrough, 2010). New start-ups are experimenting with new business models every day. Old firms are experimenting with new ways to use their data in new data products. Governments are trying to understand how to use this innovation to encourage prosperity whilst safeguarding their citizens' interests.

It is confusing for business people, governments at all levels and consumers of these new products and services. It is crucial for us to improve our understanding of what is happening and our prediction of the way that things will go with product design, consumer tastes, regulatory decisions (e.g. especially data sharing) and partnerships between firms. Research is required to help all stakeholders make choices about these complex and quickly emerging innovation ecosystems. But the concepts that underlie terms like 'innovation ecosystem' or 'digital ecosystem' are neither well defined, coherent nor commonly accepted. 
Shaw DR and Allen TFH (2017) Studying innovation ecosystems using ecology theory Technological Forecasting and Social Change. Special issue on innovation ecosystems.

The term ecosystem originated in the science of ecology. Tansley coined the term, but the idea goes back a decade before him (1935). He used ecosystem to clear up a muddle in the terminology of plant communities. The issue was that plants are not only affected by their environment, but in return they influence the soil, atmospherics and animals. By folding the physical environment in with the vegetation the first principles were changed. Plant communities were identified by plant species, the presence and abundance of which was explained by concepts like evolution, competition, predation and mutualism. Species filled niches, which are defined by a role in the community associated with resource availability. With the environment folded in, those principles fail to be explanatory. In the ecosystem concept, flows of material and energy come to the fore. Connection and flux are the hallmark of ecosystems. In ecosystems animals melt away into pathways and become a connection between food eaten and waste expelled. Animals become connectors between vegetation and the soil. If a species disappears, another is available to play its role, so animals as items may still be present in an ecosystem, but as units they do not offer explanations of ecosystem function. The functional parts of an ecosystem are things like the nitrogen recycle. Grazers might deplete vegetation changing the albedo of the ground. That changes the local climate which affects the growth of plants.

The emphasis on connections and cycling makes the ecosystem a good analogy of what happens in systems of businesses. Business systems are not so much a matter of discrete players, embodied in human business workers. Instead they amount to complicated connections that carry the flux of money, information and other resources. The business ecosystem concept becomes a more apt notion when firms depend on the Internet. Ecosystems fluxes are not always apparent to the human observer. A river flowing is tangible enough, but a nutrient cycle is not. Many connections in business are important but not tangible.

In this paper we investigate innovation in a heath app data ecosystem by focusing on Quealth. Quealth is a smartphone app that is provided by the roadtohealth group, which is in turn partnered with Samsung and other firms. These firms make use of customer-related data to produce their services (roadtohealth, 2015d). We develop a theory of innovation ecosystems using ideas from ecology and the study of complex systems. We seek to use the some of the same methods that have been used in ecology. We suggest a way of developing and unifying a theory of innovation ecosystems.

\section{Lessons from the study of natural ecosystems and complex systems}

In ecological research complexity has manifested itself in a collection of specialisations such as population biologists who study ecosystem energy flux expressed as number of organisms. Landscape ecologists study spatial pattern expressed as process function. Whereas ecosystem ecologists study energy flux, biome ecologists study the many parts as units in a sort of object based versions of ecology. But some ecologists, biologists and systems researchers have called for a more unified view of ecological research that uses ideas from complex systems to be more explicit about the process of observation and data capture in ecology (Allen and Hoekstra, 2015). When ecological phenomena are investigated using methods derived from complexity theory we find many similarities to innovation ecosystems. This similitude is not just in some superficial level that is common to all systems but in the underlying functioning and organisation of their structures and processes. Here we seek to investigate whether concepts from this complex systems method of analysing natural ecosystems can be used to study innovation ecosystems. First we set out the logic for using methods from natural ecosystems to study human innovation ecosystems. Next we theorise how to conceptualise this in the context of innovation ecosystems of human products, services that are produced by commercial and government organisations. Finally, we use our new conceptualisation of innovation ecosystems to analyse one such innovation ecosystem.

\subsection{Are concepts from natural ecosystems appropriate to use?}

There are a number of arguments which support our proposal that some concepts from the ecological sciences can be used to benefit research into innovation ecosystems. We do not advocate a wholesale translation of wellknown terms from ecology; instead we pick some specific concepts and explain their relevance and justification, separately and together in a coherent theoretical system.

Firstly, it has been noticed for some time that natural systems and business systems have marked similarities (Moore, 1993; Moore, 1996; Iansiti and Levien, 2004a; Iansiti and Levien, 2004b; Iansiti and Richards, 2006; Allen et al. 2013). Recently the innovation and entrepreneurship literature has started to use ideas that are associated with the term 'ecosystem' (Zahra and Nambisan 2012; Clarysse et al., 2014; Nambisan and Baron 2013). This research uses relatively simple biological concepts to generate valuable insights. But the biological and ecosystems research literatures each hold a vast array of rich ideas that are still to be used. Natural ecosystems and innovation ecosystems are both systems that are made up of entities joined by relationships and some of these relationships are organised in similar ways. The entities in both types of systems are heterogeneous and appear to behave at different spatial scales and at different natural frequencies. In both types 
Shaw DR and Allen TFH (2017) Studying innovation ecosystems using ecology theory Technological Forecasting and Social Change. Special issue on innovation ecosystems.

of ecosystems entities compete, attack, consume and also help each other in mutualistic situations. Here we investigate these different commercial relationships in a deeper conception than has been done before by using ecological theory of how all those processes work. Natural organisms and species compete, attack, consume each other. But also they mutually benefit each other. Another similarity between the two types of systems is in the processes that drive behaviour and change. Natural ecosystems use solar energy to power their use of nutrients to live, grow and reproduce. Innovation ecosystems also use physical energy sources to power processes that use other resources and they also use value creation in a similar way to energy, as a way to motivate and influence processes that involve their human elements. And both types of systems use information as a resource for streamlining their behaviours at different system levels.

Secondly, the interconnectedness of both types of systems with positive and negative feedback loops on different scales and with different lags makes each system difficult to study. The vast diversity of natural phenomena that can be measured by different sensors and methodologies have long made ecology a science of specialisations. A different set of students have also specialised in business and in business research so as to cope with overwhelming amounts of information. In this way that haver scaled their research. Now society is using technologies like Cloud Computing and social media to create phenomena on a much larger scale. Much smaller scale phenomena that have until recently been beyond normal human senses are becoming indirectly observable using new technologies for sensing and analysing data. Big Data and Internet of Things have unleashed tsunami of phenomena that cannot normally be accessed by naked human senses. Methods of data gathering in ecology, like the quadrat, have long presented similar opportunities for quantifying research. Both ecology and business studies share errors such as collecting data for the sake of it, reifying particular phenomena because they are tangible while ignoring other phenomena because of bias.

Thirdly, both types of systems adapt to internal and external disruption. Natural and innovation ecosystems change continuously and change happens at different scales requiring different levels of analysis. Indeed, our focus here is very much on better understanding how commercial systems adapt and innovate at the level of whole ecosystem as well as on the levels below. Natural ecosystems adapt to new entrants, environmental change and the evolution of new capabilities that are enabled by mutations. We think that the underlying processes of adaption, not always through natural selection, have some similarities that can provide useful insights. They can be mapped from one type of system to another. Note how drivers of adaption could be used in the context of both types of system. We do not say that both systems are joined at some level; just that they are similar on more levels of organisation than surface mappings. We suggest that this similarity continues below the level of the obvious surface so as to allow us to learn from one type of system and apply it to another. Experimentation always requires an analogy between the system of interest and the model system. The analogy goes both ways, so that one system may be compressed into the other. We do not go as far as actual experimentation, but we will use analogy and compression of business and natural systems into each other.

Fourthly, another commonalty between natural and innovation ecosystems is that there is a great interest by researchers in managing their outputs. Outputs of wood from forests or fish from fisheries have long been mislabelled as 'ecosystem services' (Allen and Hoekstra, 2015). We think that 'service' is the wrong term because service is offered in compensation; ecosystems are slaves to humans, and rarely get service in return. Natural ecosystems are not service suppliers in the usual meaning of service. In fact the service needs to be offered by humans to sustain ecosystems. The slovenly conventional application of 'ecosystem services' does highlight the valuable role that natural ecosystems can have in producing resources and similar valuable outputs. In this way we can think of natural ecosystems and innovation ecosystems as locked together. The idea is that complex systems can be harnessed for a purpose and that this purpose can be the production of a complex array of outputs. And the menu of outputs that it can be used to produce as well as the individual complexity of each output is much greater; which implies the solution of more complex problems for customers. A complex system such as an ecosystem is inherently harder to manage because it is external to human activity. At least human innovation ecosystems are populated by our species. In natural ecosystems internal complexity can be seen in the bewildering numbers of new compounds for drugs that are suggested. But there are direct connections between the ecosystems; nature can be mimicked as when sticky tape that is based on the soles of gecko feet (UoMassA, 2015).

The novelty of our approach is that we develop a theoretical lens for analysing innovation ecosystems from a deeper conceptualisation of the similarities between natural and business systems than has been used before. We use complexity theory as the bridge between these two types of ecosystems. We do not say that innovation ecosystems must use ideas from ecology just that some ideas are useful and here we choose several and demonstrate them. Next we will explain a coherent conceptual framework for studying natural ecosystems and then justify their use in studying innovation ecosystems. We suspect that the term 'business ecosystem' just means complicated collections of parts, a community of players. In ecology ecosystem and community are identified as different perspectives on a given biota in a place. Community is governed by evolution, 
Shaw DR and Allen TFH (2017) Studying innovation ecosystems using ecology theory Technological Forecasting and Social Change. Special issue on innovation ecosystems.

competition and predation and mutualism. It emphasizes organisms as discrete organisms, and is not much concerned with flow of material between organisms.

\subsection{A toolset of concepts from the study of natural ecosystems}

The science of ecology is made up researchers that use different perspectives to study the complex phenomena that natural systems produce. In ecology the ecosystem researchers are one of a group of scientists that also include specialists which focus on landscapes, communities, individual organisms, populations and biomes. Here we explain their differences in terms of the phenomena that they focus on. Also, we will show how each perspective provides us with a lens for studying innovation ecosystems. We use the concept of 'ecosystem' as one of six lenses for studying ecological and innovation systems.

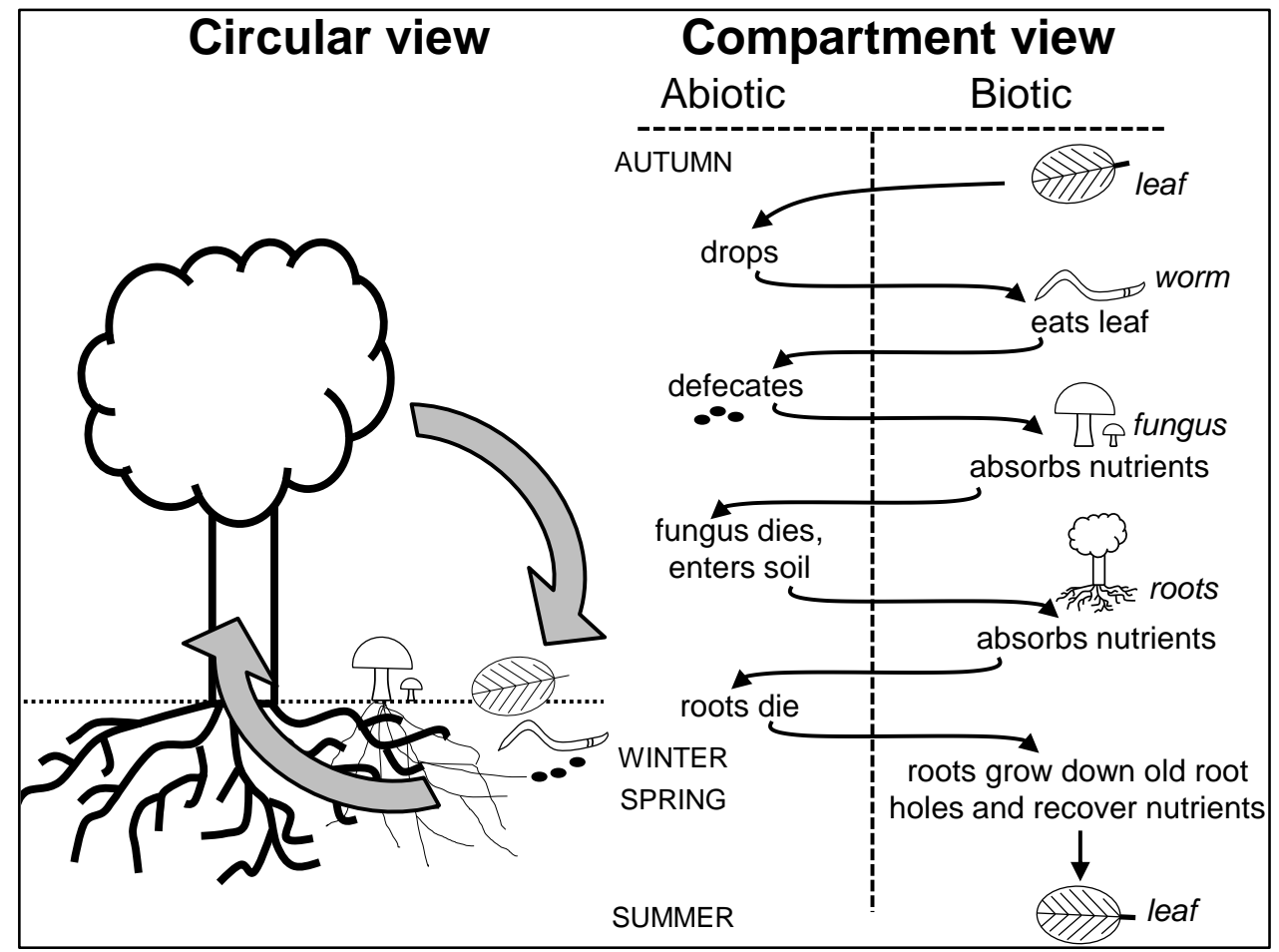

Figure 1: Nutrients cycle along pathways. Nutrients from fallen leaves pass through worms; and are absorbed by fungi, which die; and then are absorbed by tree roots, which die back in winter; leaving nutrients to be easily reabsorbed along old roots holes as roots regrow in the spring. Actions of different organisms make up the pathway, which switches between abiotic and biotic compartments (based on Allen and Hoekstra, 2015).

The ecosystem perspective: the essence of a natural ecosystem is its flows of nutrients along pathways that are enacted by different organisms and sub-systems. The organisms cease being discreet structure and disappear into the flux as connectors. For example, Figure 1 shows the recirculation of nutrients in a forest. The importance of the ecosystem perspective is not in the individual organisms or even in the individual species within it; it is in the roles that they take in how resources flow along pathways. This is particularly important for recycling resources, which is a main characteristic of ecosystems. It is the recirculation of resources that gives an ecosystem its identity. For example, rain forest soils are actually particularly nutrient-poor. The forest could not function without the heavy recycling of nutrients. No sooner than a piece of a tree is shed, for example leaves, than they are dissolved by detritus organisms that make their nutrients soluble. With the heavy rains they would be quickly flushed out of the ecosystem were they not taken up immediately by fungi tree roots. Unlike temperate forests, the nutrient capital is held in the biota not the soil. In the study of natural ecosystems the salient entities are the pathways and the roles that enact them not the particular organisms or species that move nutrients along pathways. Other organisms do the same role in different parts of the same ecosystem, or at different time periods as ecosystems change. In business this is also true, with each individual business being interchangeable with some other in terms of their general capabilities if not their specific intellectual property or the skills of specific staff. It is these capabilities that form the pathways which process resources into new forms. As in natural ecosystems the organising characteristic that makes innovation ecosystems interesting to researchers is their cycling of resources between each other and their external environment. For example, firms in the same ecosystem reuse the resource outputs, the waste or even information resources that are generated by preceding firms in their pathways (TerraCycle, 2015). This reuse also extends to reusing customers and their 
Shaw DR and Allen TFH (2017) Studying innovation ecosystems using ecology theory Technological Forecasting and Social Change. Special issue on innovation ecosystems.

data by providing complimentary services for the same customer; or services for other stakeholders that are based on what is learned from, or are by-products of, the original customer interactions. Ecosystems are a useful concept because they help us to understand process-oriented phenomena which use and reuse environmental resources to keep the system far from its equilibrium state; at equilibrium organisms are dead and firms are bankrupt. Natural systems stay far from equilibrium by using external energy and information sources. In a similar fashion, innovation systems use value creation within economic systems to motivate firms to behave in a similar way (Allen and Hoekstra 2015; Allen et al., 2009). Only recently have ecologists used the concept of profit; in the old conception organisms were only seen as depleting resources until they were all used up. Economists know better and say resources are never depleted to zero, they only get more expensive. Ecologists' proclivities to doom and gloom need to be replaced with visions of evolution to greater specialization in using more expensive resources. The use of profit in ecology has generated the concept of high and low gain. High gain is the use of concentrated resource as fuel to burn. Low gain gathers much larger quantities of low grade material that must then be processed and concentrated into something that can be used as a fuel for burning (Allen and Hoekstra 2015; Allen et al., 2009). Natural ecosystems are made up of pathways that bridge energy gradients and innovation systems are made up of business processes that are powered by how they help stakeholders to fulfil their needs.

The value co-creation system literature helps us to understand how systems of people work in multiple levels of organisation to mutually satisfy each other's needs (Ramirez, 1999). At the level of a single firm this is the essence of a business model; the description of how people and firms use capabilities to process resources in order to create value (Hedman and Kalling, 2003; Osterwalder et al., 2005; Chesbrough, 2010). The pathways of an innovation ecosystem are the 'customer journeys'. We derive the notion of customer journeys from von Uexküll's notion of umwelt or self-world for organisms (1957). The umwelt is the environment as seen by the organism, not the full material environment. For instance, humans see light, but not X-rays. A facet of umwelts is the "magic journey" of organisms. Some bird's journeys are arctic to ant-arctic, while the life journey of some grain beetles is from one end of a single grain to the other end of that one grain. For customers, this can be thought of as the 'click-journey' through a site's web pages; or the days or weeks spent looking for a product and that lead to a buying decision and a transaction; or even the serial events of a customer's life. Each event in a customer's life generates service-needs which are requirements for services in the form of information or physical products (Shaw, 2007). This is how innovation ecosystems 'reuse' customers; it is not just by sharing data with different stakeholders but also by sharing customers to provide complimentary follow-on products and services to help customers progress along their shopping journeys, or their life journeys.

Note that the term customer can be applied to any stakeholder; each staff member of each firm is also on a life journey and work journey that requires services to satisfy their service-needs. The organising principle that stands out with ecosystems is the concept of pathways that temporally join ecosystem participants. This is a valuable way to suggest how innovation ecosystems can be built and managed because it provides an explanation of their internal workings. The cycling processes of reuse that make an innovation ecosystem persist, such as using and reusing the same customers, materials and informational resources, focuses on what attracted our attention to ecosystems in the first place and gets to the heart of what sustains it.

The organism perspective: in natural ecosystems what constitutes an organism seems to be obvious; an organism is a discrete thing like a dog, an elephant or a tiger. But banyan trees that connect together with shared branches and aspen clones that together with shared roots are not physically discrete. Organisms also tend to have a unified physiological function. James Grier Miller started with the organism in his book on Living Systems (1978). He moved downscale to see the same basic functions in tissues and the cell. In his move up scale, all the way to international systems, he passed through organisations. Firms would fit in his level of organisations. His scheme is anchored to the notion of a unified physiology. The parts of a firm are linked by something like a physiology. In innovation ecosystem businesses shares of ownership, joint ventures and partnerships also make it difficult to define the discreteness of commercial and public entities. So we return to looking for another principle of organisation that helps us to understand how mutual inter-organisational innovation works. Natural organisms are commonly, although not universally, defined by a single genome. Their genes hold instructions for how they function and we suggest that this description of functionality maps on to business models in firms and other organisations. We do not suggest that a firm is similar to an organism; just that a business model that is used in roughly the same way by many organisations has two useful similarities to the genetic code shared by organisms of the same species.

A business model describes how a firm creates value by using its internal capabilities to process external resources and survive (Hedman and Kalling, 2003; Osterwalder et al., 2005; Chesbrough, 2010). Comparing firms based on their business models rather than on their locations, supply chain partners or products is appropriate when analysing innovation systems. This is because a firm must be measured on how it fulfils its role in the context of the wider ecosystem and not purely with respect to these other comparisons. Innovation at 
Shaw DR and Allen TFH (2017) Studying innovation ecosystems using ecology theory Technological Forecasting and Social Change. Special issue on innovation ecosystems.

the ecosystem level depends on the simultaneous innovation of many different capabilities at the individual firm level (Hughes, 1983). For example, some forms of 3D TV required very high resolution capabilities so that some resultuoon coud be sacrificed by repeating video across three different colours. It also depends on whether innovative business models are sustainable in terms of fostering persistence. An additional reason why a focus on linked business models is appropriate for analysing innovation systems is when the objective might be to build an innovation ecosystem. In such a situation prospective partners might not already be working together in ways that constitute ecosystem 'pathways'. For example, much has been written about the Internet of Things (IoT) (Porter and Heppelmann, 2014; Porter and Heppelmann, 2015, Economist, 2014; Manyika et al., 2015)) but little detail exists for which organisations, which products and which services should be combined to make some large scale example of an IoT ecosystem, like a smart city (Chourabi et al., 2012). However, we can conceptualise an IoT ecosystem as the system-level pathways that recirculate resources; each of which is a customer life journey and where all stakeholders have such journeys. All stakeholders in a smart city are customers and consumers of something. And the flows of information and physical resources which make the products and services that enable each stage of their journeys are described by the linked business models of the organisations within the ecosystem. The customer journey is what links separate business models, and ecosystems reuse customers or customer-related resources like data, information and knowledge. So the customer journey itself can be used to suggest a blueprint for building new innovation ecosystems.

We have already introduces von Uexküll's notion of umwelt or self-world to highlight the magic journey of customers. Von Uexküll gives the example of the female wood tick whose umwelt is made up of just three sensory inputs and three behaviours (1957). The first input is when it senses butyric acid coming from a mammal, such as a deer. This causes the tick to let go from the branch on which it waits. If it then lands on the fur of the deer the impact produces the next sensory input. Then tick processes this data signal and starts to scurry around. The scurrying behaviour leads to the next sensory input, the sense of the warm membrane of the deer's skin, which causes the final behaviour of piecing and sucking. If the tick does not sense a warm membrane then it will scurry around until reaches a new perch on another branch and the cycle restarts. It only lets go when it senses butyric acid. Experimenters have shown the tick does not identify that the warm membrane is skin or a rubber sheet holding warm glycerine. It will pierce a rubber sheet and suck glycerine. The tick has limited senses and limited behaviours. A tick's self-world is limited to just these three sensory inputs and it can only do these few behaviours. But that is enough for its to persist. Firms also have a self-world and it is based on their business model; which gives them very limited ways to sense the world and very limited behaviours. Anything that is extra to their business model is by definition superfluous and not to be encouraged. This limitation on firms' abilities to sense, understand and act is especially difficult when they try to see outside of their umwelt. For example, retailers find it very difficult to see and to understand their shoppers' umwelt. They have lots of shopper data near the end of the shoppers' journey near the decision to buy. Just before this they might know what pages on the stores' websites shoppers look at before buying; or in which stores shoppers physically looked in. Loyalty card data, cookies and other forms of identification can tell retailers this more. But the further away that you get from when customers actually buy something, in the earlier parts of the customer journey, the harder it is to get data to describe shoppers' behaviours and needs. When shoppers look on other retailers' websites or in their stores, or when shoppers ask their friends for advice on social media, retailers cannot sense any data on these behaviours and possible objectives of their shoppers.

This leads to difficulties in attributing how strongly any particular advertising campaign or promotional deal influenced any particular sale. Also, product manufacturers with little direct relations to their consumers have even less customer data than retailers (Shankar et al., 2011; Flint et al., 2014); econsultancy, 2015).

Manufacturers have little understanding of the initial stimulation in the customer for a product and how that happened. Manufacturers might use panels and surveys to understand the lives of shoppers in general but they do not know how to personalise their products or services for specific customers. More dangerous is a limited overlap between the umwelt of a manufacturer and the umwelt of its customers. The limited overlap might cause a manufacture to develop its products in a direction that diverges away from the trajectory of how its consumers' needs are changing. This suggests a cause of the success of disruptive business models, which are more in tune with the evolving needs of customers than those of the incumbents' (Christensen, 1997). However, sharing customer data with other ecosystem members who have different but complementary umwelts can help to fill in the missing piece of the data puzzle. But understanding the service-needs of a customer is different from having more customer data. Complementary umwelts from ecosystem partners provide a new context for understanding the service-needs which a firm's product or service must satisfy. For example, firms can use the events of a shopper journey, or the life goals of their life journeys, as a context for understanding the serviceneeds that their product or service must satisfy. Analysing customers' data in the context of life events, like buying a new house or having a baby, helps firms to interpret that data. A customer who starts buying new born products immediately starts getting advertisement that are aimed at pregnant women. Buying baby products provides firms with insight into a shopper's umwelt, not just sight of a shopper's umwelt, which is just sensory 
Shaw DR and Allen TFH (2017) Studying innovation ecosystems using ecology theory Technological Forecasting and Social Change. Special issue on innovation ecosystems.

data. Access to another's umwelt means accessing context as well as new sensory data. It comes from partnering with organisations that have different but complementary business models which give then different sight of the customer, different insight about the customer's life and different behavioural capabilities to share.

The population perspective: obviously firms do not produce babies but they do grow in size, depending on how you measure size. They do produce subsidiaries with separate but related business models and different degrees of legal and managerial discreetness. If we think of a business model as the genome of a firm, which describes how and why it can produce value, then we might access concepts that ecologists use to study intra and inter species competition, mutuality and the process of accommodation. Again it is not the superficial similarity of the worlds of business and nature but the rich conceptual foundations that map them together to provide novel and useful ways to understand how new digital technologies are linking firms, consumers and the public sector. We can think of firms with similar business models as being part of a single species and business model innovations as 'mutations' that may or may not be successful. In natural ecosystems the concept of a single species population is used in studies of spatial contiguity of a species or for historical explanations of which ancestors are shared. These suggest parallels in the study of innovation ecosystems; for the former in terms of spatially connected phenomena like technology clusters and for the latter in terms of from where certain business models or industrial standards arose, and perhaps why they prevailed. Population studies in biology are also concerned with carrying capacity and fluctuations of population sizes, which may suggest new methods of studying stability versus chaotic growth in industrial sectors or mitigating the amplitude of economic cycles of boom and bust. Many population biologists have missed the point made by Lotka (1956) He said that birth does not directly relate to increase in population numbers, it only provides vessels which may or may not be given resources to fill them. Thus populations are a version of conventional ecosystems (resource flux) where the output that noted is numbers of individuals. This view of populations applies particularly well to firms and growth.

The community perspective: communities are mixed aggregates of more than one species. In our approach they are firms with more than one business model that are linked in some way. In nature, the communities that we see around us are snapshots of evolving processes of accommodation, interspecies competition and mutuality. A common organising principle in the study of natural communities is the integration of organism-level phenomena. Communities are not so much aggregations of populations but are rather organisms next to organisms which are often not of the same species. For us this means that our community view focuses on how business models tightly integrate with other business models; rather than how the actions that this leads to trade resources along supply chains. Community ecologists and others tend to use organism level phenomena to try to understand the complex integration of the partially overlapping umwelts of different species. The underlying idea of a community is seen in the processes of accommodation, mutualism, competition and interference. Accommodation is the process of one species turning negative effects of another species into positive or at least neutral effects. For example, when one species becomes immune to the poison of another species the poison may become a barrier to new entrants. So the poisoner plays a useful community role. We use the idea of interference in the sense of wave interference patterns. In natural ecosystems, this is where the umwelts of different species interfere constructively and destructively with success or failure of the species over different areas and periods of time. The interference effects come from the species' different umwelts, which cause them to act at different spatial and temporal scales. For example, some birds feed from conifers rather than deciduous trees. But these conifer birds can be found in patches of oak forests and conversely one might not find them in conifer patches where a biologist might expect. The answer is that the umwelt of the bird is different from that of a biologist's. A bird experiences the world by flying over the forest at over 30 miles an hour. From the bird's perspective and according to its capabilities, many patches of forest are easily reachable, some oak patches make a fine base if surrounded by conifer patches and some conifer patches are surrounded by oak patches with little food in them. The interference pattern is caused by the layout of the patchwork quilt of different forest patches interfering with the bird's umwelt as it searches for food. The interference pattern itself is formed into the birds knowledge of available choice of the conifer birds' habitat locations. Not the actual available locations, just those of which it was aware. This is similar to the umwelt of shoppers when it is applied to retailers deciding where to locate new stores. Shopping data that includes the customers' home addresses and competitor's locations will not predict the best locations for new stores. This is because much shopping is done on the way home from work; shoppers' awareness of stores to shop from and their ability to do so conveniently is based on their work commuting journeys for certain shopping items.

In communities of firms we can also see examples of tight integration including business model complementarity; competition and accommodation. When two different business models are mutually supportive then complementarity occurs; for example when one firm provides a capability that the other lacks or finds costly. An example of this is outsourcing. Competition occurs when two business models use any of the same limited resources, not just customers. Accommodation in business, like nature, is the overall process of integration. It can be seen in business relationships that start off as purely adversarial but after business models are changed the relationship can be seen to have benefits as well. An example of this is new phone technology 
Shaw DR and Allen TFH (2017) Studying innovation ecosystems using ecology theory Technological Forecasting and Social Change. Special issue on innovation ecosystems.

that enables Uber to coordinate independent taxi cabs with people who need a ride. This new technology removed the need for large licenced taxi firms (Uber, 2015). Some taxi firms may start using similar phone apps to link more closely cabs and passengers. For communities of different species as well as for communities of different business models the way that they integrate is organising principle for our community view. For example, a supply chain can be viewed as a type of community of integrated business models with the business models being linked by a product or service-centred production process. This is similar to our ecosystem view but the organising principle of an ecosystem is the reuse of externally sourced resources such as customers, their data and their cash. A supply chain can also be viewed from an ecosystem perspective. But from a community perspective we suggest looking at how the process of business model integration changes the supply chain's constituent business models, not at how the process of how materials flow through the supply chain.

Although not much came of the idea (but it should have), some decades ago a presentation in a small subsection of the annual meeting of the Ecological Society of America was jam packed to the rafters, with a crowd outside unable to get in. It was a paper on niche separation, a well-known phenomenon of partitioning in nature. It shows species avoiding the exact pattern of resource use made by other species; an avoidance of resource competition. In nature that separation is based on evolution. But the system whose niches were being partitioned was fast food restaurants on an Oklahoma strip. The result was, despite obvious similarities in being fast food restaurants, each one differed in price, what they offered, how fast the food was, what its quality was, what the ambiance was, and so forth. There was apparently niche separation. Usually businesses are not involved in natural selection per se, and evolution is a misplaced model for commerce. Survival of the fittest is not fittest as in athletic fitness, but is rather survival of those that fit best into the environment. In this case it could be firms not surviving if they are too much like the competition. Only those with sufficiently unique postures survive.

The landscape perspective: in nature, main characteristic of a landscape is spatial contiguity on a location whose features act as structural constraints and facilitators on the flows of materials. In a business innovation setting a landscape view also includes characteristics of physical space, for example in the constraints and facilitators of the distribution of physical products or in the effects of co-locating with customers and business partners. Landscapes influence physical flows of resources in ecology and in business. But firms also experience spatially mediated cultural and regulatory effects; these are characteristics of the cultural and regulatory 'landscape' which are commonly based on spatial contiguity themselves. Examples of this are national cultures or the foot prints of national legal systems. These also constrain and facilitate flows within innovation systems. A business system example of a landscape view is the location-based characteristics of a smart city. Or the reasons why a technology cluster occurs in a specific location that are caused by characteristics of the location itself. Some firms do work explicitly with the landscape perspective. For example, United States producers of salsa adjust their product to the habits and tastes of the region. Salsas are often labelled mild, medium or hot. But one cannot find national brands that are actually 'hot' salsa in the Middle West of the US. Even if the label claims the salsa is hot.

The biome perspective: in a similar way to the landscape view another way to look at a natural system is as a biome. In nature a biome's characteristics are only indirectly based on aspects of its location. Instead, the interrelations between animals and vegetation affect and are effected by the biome's climate. For example, grasses feed grazers that in turn trim back encroaching forests based on limits set by the local climate. More water or different temperature patterns would mean shrubs and trees rather than grasses to feed the grazers. Ecological communities are not environment-determined. One community can occur in many environments and many communities occur in one environment. It is a many to many mapping caused by the specificity of named species. Biomes are not characterized by species, but only life forms. Biomes are climate-mediated in the sense that characteristics of their location cause their climate which then shapes the biome. One can recognize a biome by its physiognomy as the form of the vegetation indicates a physiological fit with the environment. Animals and vegetation can also influence the climate. Business system biomes occur at different scales which are based on supportive cultural, regulatory and even tax 'climates'. The physical, cultural or regulatory aspects of certain geographical areas produce climate effects that some business models and ecosystems of business models find supportive. For example special economic zones have legislative environments which support and limit the success of different communities of business models. On a smaller scale city planning laws do the same. From a commercial relationship perspective we suggest that smaller firms which co-locate with large customer firms are taking advantage of a biome created by the existence of the larger firm, which produces benefits such as ease of delivery, closer working relationships and an inter change of high quality staff. Our landscape view considers the passive physical influences of co-location in a particular location. In contrast, our biome view considers the influences of local climates that were actively shaped by the firms themselves over time. This shaping includes lobbying, influencing public sentiment and attracting talent to the area. Landscape criteria are direct constraints of the physical location. The biome perspective is directly based on the location's climates and climates are in turn based on the physical location, but they can be influenced. 
Shaw DR and Allen TFH (2017) Studying innovation ecosystems using ecology theory Technological Forecasting and Social Change. Special issue on innovation ecosystems.

\begin{tabular}{|c|c|c|}
\hline Perspective & Natural ecosystem organising principles & Innovation ecosystem organising principles \\
\hline Ecosystem & $\begin{array}{l}\text { Defined by recycling flows of nutrients along } \\
\text { pathways made up of living subsystems' } \\
\text { which are organised into process-orientated } \\
\text { roles; connects living and non-living } \\
\text { subsystems; energy gradients power } \\
\text { recycling of scarce nutrients, e.g. a rainforest. }\end{array}$ & $\begin{array}{l}\text { Defined by flows of services to a customer } \\
\text { and resources related to that customer, which } \\
\text { are recycled by business models linked into } \\
\text { pathways; powered by value co-creation for } \\
\text { stakeholders; innovation in the form of new } \\
\text { business models that reuse scarce customer- } \\
\text { related resources in new ways or in ways that } \\
\text { co-create value more directly, e.g. organising } \\
\text { around a common customer journey. }\end{array}$ \\
\hline $\begin{array}{l}\text { Organism/ } \\
\text { Type of } \\
\text { business } \\
\text { model }\end{array}$ & $\begin{array}{l}\text { Defined by similar genomes which code for } \\
\text { specific capabilities and behaviours, } \\
\text { producing an organism's umwelt, the 'self- } \\
\text { world'; an umwelt is a particular sensor } \\
\text { subset of available phenomena, of ways of } \\
\text { processing data and of abilities to then act. }\end{array}$ & $\begin{array}{l}\text { Defined by the similarity of type of business } \\
\text { model which describes specific ways to } \\
\text { create value and a specific umwelt; business } \\
\text { model umwelts constrain access to data, } \\
\text { understanding of insights and available } \\
\text { actions; such specialisation suggests } \\
\text { collaboration in systems of linked business } \\
\text { models that recycle scarce customer-related } \\
\text { resources. }\end{array}$ \\
\hline Population & $\begin{array}{l}\text { Defined by spatial contiguity of a species or } \\
\text { historical explanations of which ancestors } \\
\text { are shared; insights about population } \\
\text { carrying capacity and fluctuations. }\end{array}$ & $\begin{array}{l}\text { Defined by the co-location of copied business } \\
\text { models, or the ancestry/ provenance of } \\
\text { business model ideas and implementation } \\
\text { methods; insights about market capacity and } \\
\text { size fluctuations. }\end{array}$ \\
\hline Community & $\begin{array}{l}\text { Defined by modes of tight integration by } \\
\text { mixed species; snapshots of evolving } \\
\text { processes of interspecies accommodation, } \\
\text { competition and mutuality; exhibited by } \\
\text { interference patterns from different } \\
\text { interacting umwelts. }\end{array}$ & $\begin{array}{l}\text { Defined by how firms with different roles } \\
\text { work tightly together, e.g. integrating } \\
\text { business models in a supply chain; a snapshot } \\
\text { of evolving business relationships; } \\
\text { interference effects e.g. variation of } \\
\text { coopetition between pure competition to } \\
\text { mutual partnership over different situations. }\end{array}$ \\
\hline Landscape & $\begin{array}{l}\text { Defined by spatial contiguity in a location; } \\
\text { location features constrain and facilitate the } \\
\text { flows of nutrients and energy. }\end{array}$ & $\begin{array}{l}\text { Defined by spatial contiguity in a location; } \\
\text { location features constrain and facilitate the } \\
\text { flows of resources; location features are } \\
\text { cultural and legal not just physical, e.g. the } \\
\text { situation of a smart city. }\end{array}$ \\
\hline Biome & $\begin{array}{l}\text { Defined directly by climate and only } \\
\text { indirectly by location; inter-relations of } \\
\text { organisms affect and are effected by the } \\
\text { biome's climate. }\end{array}$ & $\begin{array}{l}\text { Defined by supportive cultural, regulatory } \\
\text { and tax climates in specific locations; helps } \\
\text { specific communities of business models } \\
\text { flourish; climates are actively influenced by } \\
\text { inhabitants e.g. lobbying for economic zones } \\
\text { or city planning changes. }\end{array}$ \\
\hline
\end{tabular}

Table 1: Six lenses for studying innovation ecosystems from the natural ecosystems literature (Allen and Hoekstra, 2015).

\section{Research Method}

\subsection{Sample and context}

Our study of a heath data ecosystem is a multi-actor as well as a multi-level investigation. So we take an interpretive stance, because human interaction and valuation is subjective. We iterate around a hermeneutic circle, between ecosystem, organisational and individual level perspectives so as to consider an interdependent whole (Klein and Myers, 1999; Chalmers, 2004). Using ecological concepts in the innovation domain is novel, which suggests a qualitative approach because our investigation is concerned with initial questions of 'how' and 'why' rather than of 'how many'. In order to answer 'how' and 'why'-type questions we follow Yin (2003) and use a case study approach. This is fitting for research onto contemporary phenomena, which we have no control over, and that includes business relationships between many different firms. It is also a valid approach for 
Shaw DR and Allen TFH (2017) Studying innovation ecosystems using ecology theory Technological Forecasting and Social Change. Special issue on innovation ecosystems.

information systems research (Benbasat et al, 1987; Lee, 1989) and the inter-firm relationships here take the form of the flows of information. The organising characteristic of ecosystems is the cycling of resources internally and with their external environment. So the ecosystem pathways are our level of analysis.

We use a single case study because it is what Yin calls a revelatory case (2003). Yin defines a revelatory case as one displaying "phenomenon previously inaccessible to scientific investigation" (p. 42). Many firms work together in networks and supply chains but the case phenomena of the Quealth ecosystem is revelatory because of the use of new digital and information processing technologies such as phone apps and health data analytics. Quealth is owned by the roadtohealth group, one of a new set of businesses that combine consumer apps, analysis of consumers' health-related data and digital services mediated via a global communications brand such as its partner Samsung. Our choice of digital case firms helped us to understand the structure and processes of information flows between the firms in ways that that non-digital case firms would not give us (Siggelkow, 2007). The digital foundation of this ecosystem amplifies the amount of information flowing. Using a single case has external validity implications, i.e. generalisation implications (Lee, 1989), but a single case is justified at the outset of theory generation (Benbasat et al, 1987) and although it may limit statistical generalisation is does not degrade analytic or theoretical generalisation (Robson, 2002). This is consistent with the theory building objectives of this study. We have used different data collection methods and different sources because we are concerned with dynamic phenomena (Eisenhardt, 1989).

\subsection{Data}

Over a two and a half year period interviews ranged from fifteen minute informal conversations to semistructured interviews with senior management of Quealth. Access to, and understanding of, the business context of Quealth was also helped when the firm hosted an MBA dissertation which ended with a formal presentation to senior management and staff. The focus of the firm-level analysis was Quealth and its app. But we sought to understand how an innovation ecosystem might develop around the firm's app. So, in the same period we also interviewed senior data analytics managers from the other organisations in the case; these were a retail pharmacy brand, a provider of healthcare software and data services, and an ex senior Public Health manager from the NHS (see

\begin{tabular}{|c|c|c|}
\hline Interviewees & Organisation & Date (durations varied from 30 minutes to 2 hours) \\
\hline CEO & $\begin{array}{l}\text { Quealth, roadtohealth } \\
\text { group }\end{array}$ & $\begin{array}{l}\text { Key interviews: } 27 \text { January 2015, } 10 \text { June } 2015,22 \\
\text { September } 2015 \text { and } 30 \text { March } 2016 \text { plus various face to } \\
\text { face, telephone and email contacts from September } 2013 \\
\text { to March } 2016 \text {. }\end{array}$ \\
\hline $\begin{array}{l}\text { Head of Clinical } \\
\text { Governance }\end{array}$ & $\begin{array}{l}\text { Quealth, roadtohealth } \\
\text { group }\end{array}$ & $\begin{array}{l}\text { Key interviews: } 27 \text { January 2015, } 10 \text { June 2015, } 22 \\
\text { September } 2015\end{array}$ \\
\hline $\begin{array}{l}\text { Director of } \\
\text { Innovation }\end{array}$ & roadtohealth group & Key interviews: 27 January 2015, 10 June 2015 \\
\hline Head of Finance & roadtohealth group & Key interviews: 27 January 2015, 22 September 2015 \\
\hline MBA intern & roadtohealth group & Various interviews, supervisor meetings in summer 2015 \\
\hline Head of analytics & $\begin{array}{l}\text { Healthcare software } \\
\text { firm }\end{array}$ & Key interview: 4 August 2015 \\
\hline Head of Analytics & $\begin{array}{l}\text { Retail pharmacy } \\
\text { brand }\end{array}$ & $\begin{array}{l}\text { Key interviews: } 11 \text { November } 2015 \text { plus various } \\
\text { telephone and email contacts from September } 2013 \text { to } \\
\text { November } 2015 \text {. }\end{array}$ \\
\hline
\end{tabular}


Shaw DR and Allen TFH (2017) Studying innovation ecosystems using ecology theory Technological Forecasting and Social Change. Special issue on innovation ecosystems.

\begin{tabular}{|l|l|l|}
\hline $\begin{array}{l}\text { Ex senior Public } \\
\text { Health manager }\end{array}$ & $\begin{array}{l}\text { Public Health } \\
\text { England, NHS }\end{array}$ & $\begin{array}{l}\text { Two key interviews in November } 2015 \text { of between } 30 \\
\text { minutes and } 1 \text { hour plus various informal conversations in } \\
\text { person and by email. }\end{array}$ \\
\hline
\end{tabular}

Table 2). Data from meeting notes, meeting transcriptions, telephone conversations together with informal and chance conversations were supplemented by firms' internal reports and the content of their websites and government websites. The interviews were conducted in the offices of the organisations that the staff worked for. A late version of this paper was validated by Quealth senior managers (roadtohealth, 2016a; roadtohealth, 2016b).

\begin{tabular}{|c|c|c|}
\hline Interviewees & Organisation & Date (durations varied from 30 minutes to 2 hours) \\
\hline $\mathrm{CEO}$ & $\begin{array}{l}\text { Quealth, roadtohealth } \\
\text { group }\end{array}$ & $\begin{array}{l}\text { Key interviews: } 27 \text { January 2015, } 10 \text { June 2015, } 22 \\
\text { September } 2015 \text { and } 30 \text { March } 2016 \text { plus various face to } \\
\text { face, telephone and email contacts from September } 2013 \\
\text { to March } 2016 .\end{array}$ \\
\hline $\begin{array}{l}\text { Head of Clinical } \\
\text { Governance }\end{array}$ & $\begin{array}{l}\text { Quealth, roadtohealth } \\
\text { group }\end{array}$ & $\begin{array}{l}\text { Key interviews: } 27 \text { January 2015, } 10 \text { June 2015, } 22 \\
\text { September } 2015\end{array}$ \\
\hline $\begin{array}{l}\text { Director of } \\
\text { Innovation }\end{array}$ & roadtohealth group & Key interviews: 27 January 2015, 10 June 2015 \\
\hline Head of Finance & roadtohealth group & Key interviews: 27 January 2015, 22 September 2015 \\
\hline MBA intern & roadtohealth group & Various interviews, supervisor meetings in summer 2015 \\
\hline Head of analytics & $\begin{array}{l}\text { Healthcare software } \\
\text { firm }\end{array}$ & Key interview: 4 August 2015 \\
\hline Head of Analytics & $\begin{array}{l}\text { Retail pharmacy } \\
\text { brand }\end{array}$ & $\begin{array}{l}\text { Key interviews: } 11 \text { November } 2015 \text { plus various } \\
\text { telephone and email contacts from September } 2013 \text { to } \\
\text { November } 2015 \text {. }\end{array}$ \\
\hline $\begin{array}{l}\text { Ex senior Public } \\
\text { Health manager }\end{array}$ & $\begin{array}{l}\text { Public Health } \\
\text { England, NHS }\end{array}$ & $\begin{array}{l}\text { Two key interviews in November } 2015 \text { of between } 30 \\
\text { minutes and } 1 \text { hour plus various informal conversations in } \\
\text { person and by email. }\end{array}$ \\
\hline
\end{tabular}

Table 2: List of interviewees and their roles and organisations.

The long term relationship with Quealth started in September 2013. It deepened with a joint funding bid in summer 2014 and again with an MBA internship project in summer 2016. The relationship continues to develop with guest lecturing by the CEO at one author's university in September 2016. The prolonged relationship with the case participants helped to reduce validity reactivity and to increase trust as well as disclosure. These interviews provided many chances for unstructured exploration of the case firms' business models and information requirements. All through the period of the research there was regular informal email and telephone conversations with the participants. All together these regular communications were valuable opportunities for testing how well our ideas fitted and were relevant to the participants' interpretations of their firms (Suddaby, 2006).

\subsection{Data Analysis}

We used a qualitative data analysis process because we were studying how groups of firms innovate together by mutually helping each other with information resources. And the different contexts of the individuals and their firms had an influence on the help that they would need. A qualitative approach also enabled us to show 'what 
Shaw DR and Allen TFH (2017) Studying innovation ecosystems using ecology theory Technological Forecasting and Social Change. Special issue on innovation ecosystems.

precedes what' in complex organizational processes and to 'cycle back and forth' between variables and processes (Miles and Huberman, 1994). We used a hermeneutic approach that was based on Klein and Myers' hermeneutic analysis principles (1999). In hermeneutic analyses an understanding of the whole system comes from studying a system's parts and their different interrelationships. And by contrasting these with preconceptions and new insights in a circular interpretation process. Hermeneutics is a cyclic process which examines the interrelationships between parts and whole, parts and parts, and the whole and its environment. The aim is for each cycle to improve the understanding of the phenomena using new data and new perspectives.

In our study we followed a hermeneutic cycle that included each of the Allen and Hoekstra' six lenses for studying natural and innovation ecosystems (2015). In each of these six stages we also considered our data from the perspective of each of the case organisations. For example, we asked participants what extra information they would find useful, such as customer requirements data. We also tried to find out what information they each had access to which could potentially be used by other participants. We found this reflexive and cyclic approach particularly useful for generating and testing ideas for sharing data and other resources. Especially resources that were not currently shared or were not shared with particular participants. In this situation the group of firms wished to innovate but there were many potential ways to do this with no clear way to prioritise. Our iterative approach increasingly helped us to understand the participants' needs for information together with an understanding of what information was available. For example, learning the information needs of one firm could then be used to focus our interactions with another firm to see if they had this information or if they knew where to get it.

Klein and Myers' principles (1999) for conducting and evaluating interpretive field research are as follows:

1. The Fundamental Principle of the Hermeneutic Circle - humans interpret sensory data by cycling between the parts and the whole of a system. Data, organisations and material objects, plus researchers and participants are counted as parts.

2. The Principle of Contextualization - researchers must bear in mind the social and historical 'back story' of the case. How and why the case data was produced by the case phenomena.

3. The Principle of Interaction between Researchers and Subjects - researchers must assess how the case data is socially construct by participants interacting with them. Researchers must consider and question their own assumptions.

4. The Principle of Abstraction and Generalization - researchers must identify links between the idiographic level of their investigation and the wider literature. This is to test any theoretical contributions and to link it to the appropriate literatures.

5. The Principle of Dialogical Reasoning - researchers must be honest and forthcoming with their own initial biases and preconceptions. They should ask 'how were we thinking when we started this research?'. They should seek to understand how and why their initial conceptual lens changed. This can help researchers to understand how different ideas led to an understanding, or misunderstanding, of the case.

6. The Principle of Multiple Interpretations - researchers must be aware that it is possible for researchers and participants to have different interpretations of the same situation because of their different perspectives. In the social sciences this is referred to as the Rashomon Effect and it can lead to special insight as well as to bias (Roth and Mehta, 2002).

7. The Principle of Suspicion - researchers must watch for socially created distortions of participants' accounts. These distortions are not simply truths or falsehoods; rather they are caused by social context. Common 'figures of speech', ideas, routines, values or standards can subtly distort participants' data. For example the contrasting attitudes to personal health data held by patients and some commercial firms may lead to different participant accounts. Especially when uses of such data are fast changing and not generally agreed by society - such as with technological innovation. This is a danger as well as an opportunity because it signals the social forces at work in the case.

These principles should be used together and not as separate items in a check list. Hermeneutics is a processual, multi-perspective and iterative approach that is particularly appropriate for our investigation of how multiple participants seek to develop new ways of innovating together.

\section{Case analysis}

\subsection{Case background}

Our research focus is on innovation ecosystems so we choose a case site that combines firm-level phenomena and ecosystem-level phenomena. We seek to investigate how innovation works at different levels so we choose 
Shaw DR and Allen TFH (2017) Studying innovation ecosystems using ecology theory Technological Forecasting and Social Change. Special issue on innovation ecosystems.

a case firm that is in the process of building its own ecosystem by inviting new partners. Our objective is to understand how and why firms work together in a manner that might be labelled an 'ecosystem', and how theory might suggest ways to construct new ecosystems. With that in mind, we choose a health-related set of organisations to test our conceptualisation of an innovation ecosystem. This ecosystem is only partly formed so we can study how it could be developed. Some of the organisations already work together and some could potentially do so; here we analyse why they could and how this could be. Our case uses data from smartphone apps because of the immaturity and novelty of these technologies and the ways that they are starting to be used. We focus on the data flows rather than the flows of other resources because flows are a main characteristic of our ecosystem analysis framework; in fact they are the principle organising construct of a natural ecosystem. Also, data is a resource flow that links all levels of stakeholders in this system from consumer, to firm to the NHS, the UK's national healthcare system.

Quealth is a smart phone app that is produced by the roadtohealth group which is partner of Samsung, the mobile phone manufacturer. Quealth enables users to understand their risk of developing several major diseases including diabetes, emphysema, dementia, cardiovascular disease and six cancers (Google Play, 2015). A user answers a short questionnaire and the Quealth algorithm calculates their 'Quealth Score', which is the likelihood of them developing a disease. It feeds back the results via an app that is available on Google Play and iTunes.

"The health journey comprises five interactive modules - health assessment, health planning, health coaching, health tracking and health motivation" (roadtohealth, 2016a).

Then the users are able to use the app to get suggestions for lifestyle changes which they can act on and then retake the questionnaire for an updated score. In this way users are motivated to frequently interact with the Quealth app to share their data and act on suggestions in a ongoing process. The Quealth algorithms have produced more than 350, 000 Quealth Scores and it is medically validated by the School of Medicine at The University of Nottingham (roadtohealth, 2015f; 2015g).

"The app achieved 65,000 downloads worldwide since launching in October 2015 , principally in the UK and Europe, the United States and Australia” (roadtohealth, 2016a).

Partners of roadtohealth include Patient, a healthcare website, the bank, HSBC; Public Health England, executive agency of the Department of Health in the UK that supports public health professionals across; the mobile device manufacture Samsung; the insurance company AVIVA; and the UK's Royal Society for Public Health (roadtohealth, 2015e).

\subsection{Case analysis}

Our research question is 'how can innovation ecosystems be designed?' So we focus on pathways that recirculate resources to form the identity of some recognisably discrete system of firms and other organisations. We use the definitive characteristic of ecosystems as a perspective for examining the firms in the case ecosystem. We also examine the case using the underlying characteristics of the other ecological criteria that we have described above: the organism perspective, population perspective, community perspective, landscape perspective, biome perspective.

The ecosystem and organism perspectives: an ecosystem perspective is defined by pathways that recycle resources. Figure 2 shows the recirculation of data that is based on customer relationships and customer attention. The recirculation is between the customer and different firms in the innovation ecosystem. Users initially use Google to find potential sources of answers to their health concern, e.g. a worry about contracting cardiovascular disease that is stimulated by thoughts about growing old when they reached their $40^{\text {th }}$ birthday; or an illness suffered by a relative. Users then click on one of the top ranked web pages in the list that Google provides. The Patient.info web site has more than 18 million visits a month by both patients and health professionals around the world (Patient, 2015a). Patient is a source of information and advice and it is funded by EMIS (Egton Medical Information Systems Ltd). It enables NHS patients to manage their own healthcare online, including booking appointments and ordering prescriptions as well as viewing their own health records (Patient, 2015b). Its business model is to use its advice services to attract the attention of patients and health professionals in the form of website visits and then use this to earn revenues. The large traffic to the website is important because it gives the website a higher place on the Google search listings, a positive feedback loop which is enabled by the attractive content on the sight as well as Patient's search engine optimisation (SEO) capabilities. SEO techniques drive user traffic to websites by helping them to gain higher placement on search engine rankings, so that users will be more likely to visit them. This is critical for gaining customer attention because there are many health-related websites on the web. So customer attention is a very scarce resource. After reading the website users then look for advice, which could suggest using the Quealth app to investigate their concerns about cardiovascular disease. More than 120,000 people use the app via the Patient web site and when it is accessed via Patient it is called 'MyHealth', not Quealth (Patient, 2015c). 


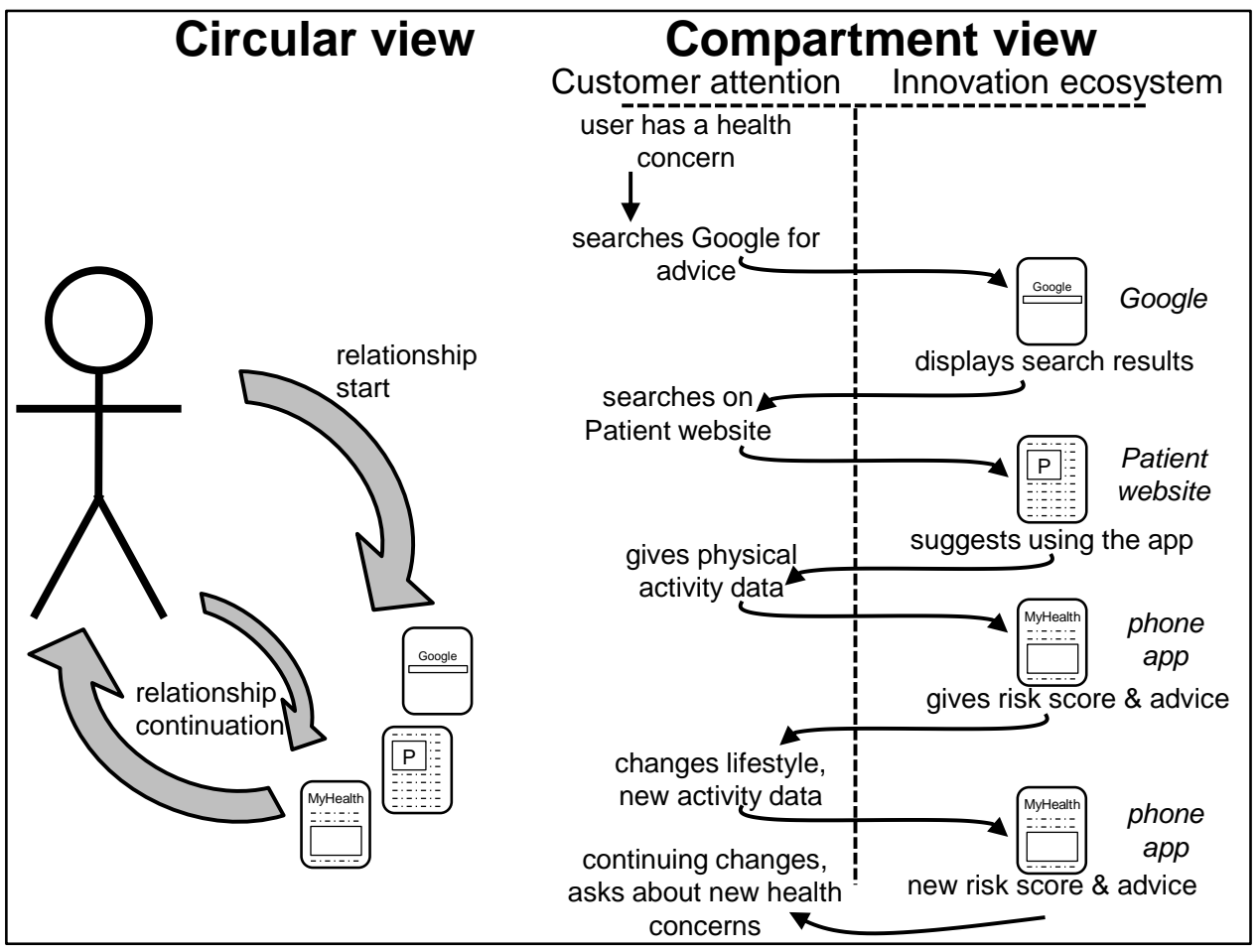

Figure 2: Customer data and data services cycle along digital pathways. The scarce resources are the customer relationship and customer attention; data is secondary. A user with a health concern searches Google for help; finds the Patient website and finds the phone app; the app captures the user's answers and activity data to generate a risk score and lifestyle advice, which changes user behaviour; and generates new activity data. Actions driven by different business models make up the pathway, which switches between customer and innovation ecosystem compartments.

The app asks the users to answer several questions about themselves covering lifestyle, diet and key biometrics as well as personal and family medical history. At the end of questionnaire the app calculates a 'Patient $\mathrm{Q}$ Score' for the user, which is a ranking from 1 to 100 . A score of 1 means a poor state of health and a score of 100 means an optimum health state for the disease that they are answering questions about (Patient, 2013). The calculation takes into account data from a population of people with the same age, gender and race as each user (roadtohealth, 2015d). As well as a risk score the user gets tips and solutions for changing their lifestyle, that are customised to each user's weak points in their health, based on by their answers. Users are encouraged to set simple health goals to improve their scores, which motivates them to take the health assessment again at a later date. This sets up a cycle as users revisit the app for retesting, new advice and motivational messages. Messages include in-app interactional, coaching dialogue, push notifications, SMS messaging and email as well as more general social media messaging such as those with the \#MondayMotivation hashtag that are retweeted on the Quealth Twitter feed (Twitter, 2015; roadtohealth, 2016a). The apps starts off by providing a single transaction service but the lifestyle suggestions, encouragement and retesting opportunities convert the transaction into an ongoing relationship.

The firms in the case function according to their business models to 'recycle the customer' between them. They each make use of the relationship with the user in different ways depending on what information they glean from the data that the user gives to the app. The customers' initial attention is converted into a full customer relationship, then the initial relationship becomes tighter and more focused as the cycle of recalculated risk scores and advice in exchange for new customer data, is repeated. The scarcest resource is not the customer data because data can easily be reused and shared. The scarcest resource is the relationship with the customer and customer's limited attention that initiates it. A potential example of 'recycling' the user relationship to help the user along their customer journey would be if appropriate activity and risk data from users of the app were to be augmented with users' clinical data from their GPs. EMIS provides the Patient website. EMIS also provides data services for family doctors (GPs) including Q Risk, which is separate to roadtohealth's services. Q Risk enables GPs to give risk scores to patients when they come into the surgery. But incorporating the roadtohealth's umwelt would provide new sensory data because it is a 'live dataset' of users and because it based on a live network of users rather than a completely historical dataset like Q Risk. In addition to this, accessing roadtohealth's umwelt would provide new capabilities for GPs to use such as a personal motivation, monitoring and advice service via users mobile phones. Currently, GPs only use Q Risk in their surgery and 
Shaw DR and Allen TFH (2017) Studying innovation ecosystems using ecology theory Technological Forecasting and Social Change. Special issue on innovation ecosystems.

only infrequently. Incorporating the senses and capabilities of roadtohealth's umwelt in the form of users own phones forms new pathways and radically tightens the information sharing cycle. This cycle could potentially form a positive feedback loop that would motivate users to change their lifestyle and improve their health risk scores.

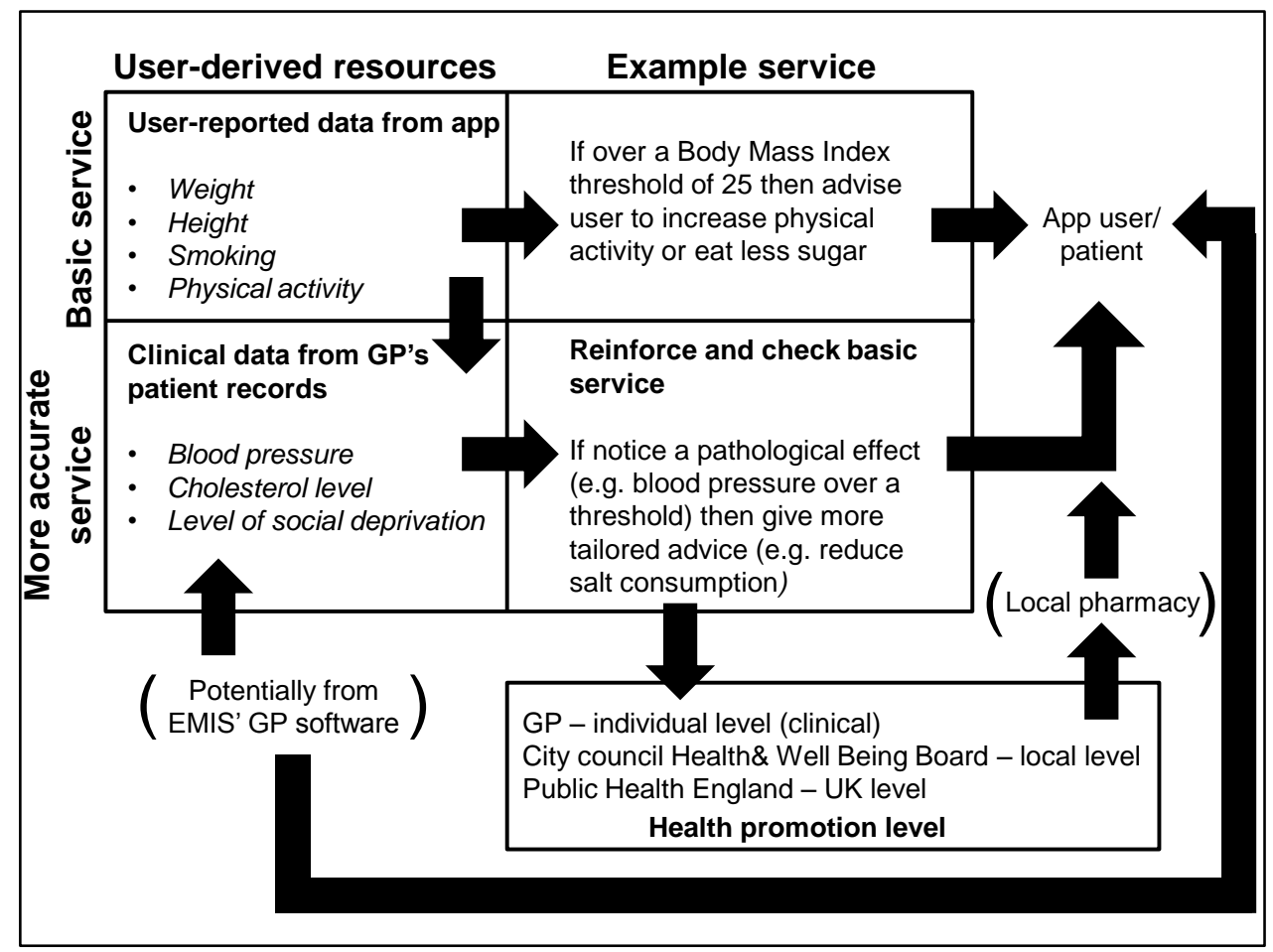

Figure 3: Potentially 'recycling' the user relationship to help the user: user-reported data from the app could potentially be checked and augmented with more precise and extra clinical data. The basic service could be augmented with a more tailored service which targets more fundamental clinical issues. A patient's GP gets access to app data as do other levels Health Promotion. Local pharmacies could also help with products and tailored advice. (Parentheses indicate potential business models, arrows indicate pathways).

Any single piece of customer data itself is only of secondary importance next to permission to use that data; a return channel for repeat selling of the data services that the data produces back to the customer; and the contextual knowledge of the service-needs of the customer. Contextual knowledge needs some entity to have a long term relationships with the customer. Contextual knowledge requires adding together many pieces of data in a time series in order to produce trends and historical precedents. Cause and effect relationships require process data. in the case, a series of interactions with a user enables roadtohealth to describe the user's 'customer journey'. The customer journey is the chain of events and associated service-needs that an individual customer goes through. The arrows on right hand side of Figure 2 show a short set of process journey stages that use the app. The requirements for information and advice are the service-needs that are generated by the user's objective of wanting to know their health status and then wanting to become healthier. In this way a customer journey suggests some of the new pathways that could constitute an innovation ecosystem.

The community perspective: a community perspective is defined by how firms with different roles work tightly together in a changing process of mutual accommodation. Accommodation is particularly evident in our case as firms seek to find uses for new technologies. In fact, as we have worked with roadtohealth over two years it has become evident that firms in its innovation ecosystem does not work very tightly together compared to the deep integration a natural communities. The array of partners that are displayed on roadtohealth's website are only a small subset of the potential partners that could use information on the situations and behaviours that roadtohealth has access to via its umwelt. By 'situations' we mean much more than access to users' data; we mean accessing the changes in our culture that make it normal to carry a small mobile device around all the time; to frequently consult it and act on its advice; and to use non-medical, and even non-human agents, to satisfy personal health objectives. Much more could be done in forming a community around the data and capabilities of roadtohealth's umwelt. For example, all retailers have great difficulty in attributing how strongly any particular advertising campaign or promotional deal influenced any particular sale because their umwelts focus on the transaction stage of the customer journey, not earlier and later stages (econsultancy, 2015). 
Shaw DR and Allen TFH (2017) Studying innovation ecosystems using ecology theory Technological Forecasting and Social Change. Special issue on innovation ecosystems.

A community perspective looks at how the process of business model integration changes the supply chain's constituent firms. Another example of how roadtohealth has changed is its move from website-based customer relationships to relationships that are supported by apps on mobile phones. In 2015 roadtohealth systematically restructured itself into a modern digital firm in response to being invited to join Samsung's S Health app platform for its phones. S Health is a platform that app developers, hospitals, healthcare providers, insurance firms and pharmaceutical firms use to share appropriate data between themselves and different devices. It is focused on personal health monitoring and uses the special personal data from sensors on mobile devices that people wear or carry. These are a subset of IoT devices that are commonly called 'wearables' (Bell, 2014). But $\mathrm{S}$ Health only provides a method of connection it does not say who or what should connect and it does not provide a logic for suggesting new firms or devices to connect with. It does however give roadtohealth access to Samsung's health platform and the many users of the new Samsung S6 phones (roadtohealth, 2015a). Another change that roadtohealth made to accommodate Samsung was the development of a new governance structure. The algorithms that the Quealth app is based on were already clinically validated by the School of Medicine at The University of Nottingham (roadtohealth, 2015b). But roadtohealth decided to broaden and deepen their umwelt by starting to recruit staff including clinical assistants for detailed service configuration, clinical testing and quality assurance (roadtohealth, 2015a). The firm also developed academic and clinical expert panels to provide expert insight into Quealth's forward development (roadtohealth, 2016a). The Patient website also made changes, in January 2013 it announced a partnership with roadtohealth that provided thousands of visitors to the website with roadtohealth's app's service, which was branded as 'MyHealth' (Patient, 2015). These changes are examples of how one firm changes its structure, its staff, its website or its service in response to another firm joining the community. It is important to emphasise that the firm does not change its inherent business model; it changes its activities by accessing external capabilities in response to drivers. In our case these drivers were external drivers, such as direct competition for customers or a realisation that the business is a digital business not an old style business. Or they were internal drivers such as the motivation to grow the firm into the new market in personal healthcare monitoring apps and data. Both are examples of different types of accommodation that the firms displayed.

The population perspective and the landscape perspective: a population perspective is defined by a concentration of similar business models in the same location, like Silicon Valley in the US. This perspective is also defined by the ancestry or provenance of business model ideas and implementation methods over time. This case study is not concerned with discrete locational phenomena, such as tech clusters. Also, other geographical effects and the scale of analysis of our investigation did not cover the 'longitudinal dimension' of the dynamics of the business model over a large period (Hedman and Kalling, 2003).

The biome perspective: a biome perspective is defined by the how cultural, regulatory and tax climates in specific locations influence the success of communities of business models. In our case recent cultural changes strong influenced users' attitudes to healthcare apps and to how firms used their personal data. Also, changing regulatory climates promise to be a stronger influence on how firms can use customer data in the future. For both types of climates we choose a UK scale of biome for our case; even though the Quealth service is distributed globally by the World Wide Web. Our focus on the UK is purely based on our access to case data on the UK and EU cultural and data protection climates. Our biome analysis could also be focused on a global biome, a biosphere, or on another region such as the US. Equally we could have focused on smaller scale biomes but the large scale umwelts of business models that use the World Wide Web point to a larger scale focus for our case. Different cultural and regulator climates influence business model success at different scales so the choice of a national scale is a question of research design. Biomes are not scale dependent so is not based on some scale-related characteristic.

The cultural climate in the UK has shifted as attitudes to using mobile devices to measure one's self and gain healthcare advice have changed. There has been strong use of the technologies that are grouped under the heading of 'The Quantified Self' and many new firms have started which use apps, mobile devices, wearable devices and sensors to measure their owners activities and physiological states (Favaro and Nair, 2015). It would be very interesting to compare our UK cultural biome to other cultures with stronger attitudes to accepting new consumer technologies, like Japan, or to compare sub-cultures within the UK, e.g. the capital city versus the countryside. It would also be interesting to study the process of cultural change in response to technological change and how this affected the biome's cultural climate. However, because of space constrains we will focus on the regulatory climate of the UK biome.

The regulatory climate in the UK is focused on protecting personal data. Digital technologies have very quickly advanced to the point where misgivings about what firms should be allowed to do with personal data are common. Different groups of people have different attitudes to the use of their personal data (Lewis and Liao, 2014) and regulators are seeking to understand and clarify how this affects their role (CMA, 2015; ICO, 2014). The regulatory climate in the UK is indirectly influenced by a European-level climate (Smith, 2015a) and by the US 
Shaw DR and Allen TFH (2017) Studying innovation ecosystems using ecology theory Technological Forecasting and Social Change. Special issue on innovation ecosystems.

climate (Smith, 2015b). Public awareness and regulator frameworks have not kept up with technological innovation. Changes will be made to the current regulator frameworks at the level of UK law and at the level of EU law, which it is obliged to be consistent with (London Economics, 2013). People are particularly sensitive about their personal health data. But the public's attitude to privacy is complicated and multifaceted. For example, there is a 'privacy paradox' whereby people might intend to keep their personal information secret but they still share it with firms (Bélanger and Crossler, 2011). As one might expect, there has been much interest in privacy research in the information systems literature (Dinev, 2014).

In the UK the regulatory climate for using customer data is in the process of change. We can see how new technologies have produced new capabilities; new umwelts. Technologies that have been incorporated into new business models which start-up firms have used in the form of healthcare apps and new data services. But the public has started to become aware of how firms could harm them by using their personal data. An example of this would be an unhealthy lifestyle that leads to a higher health insurance premium, or to people not being able to get insurance. This rising awareness of there being liabilities as well as benefits has produced a call for stricter data protection laws in the press and a reassessment of UK and EU law. The EU has the authority to apply legislation within the UK but to enact it may need new or amended legislation passed by the UK Parliament. And EU data protection law is influenced by public attitudes in its 28 member states (Parliament, 2015). This dependence on larger-scale processes makes regulatory climate change nearly as slow, but just as inexorable, as that of physical climate change. So the data regulation biome of the UK has a link to a higher EU level. It is different to the nearby biomes of other EU states because of its different history; but there are similarities between EU state biomes because some of that history is shared. Also, the data regulation climates of all EU states are in a process of change which is driven by public sentiment; technological development and adoption; and business model innovation.

\section{Discussion}

\subsection{Disrupting ecosystems: adjacent business models, umwelts and new ecosystems pathways}

Our case shows how a business model is built out of technological and human capabilities (Hedman and Kalling, 2007), which have limitations on what can be sensed, understood and acted on. These limitations lead to the concept of the umwelt of the business model. Von Uexküll's umwelt has been used extensively in systems research and business practice by Checkland (1999). Here we use it in a novel way that implies a challenge and a danger. First, the challenge is that business model constrains a firm's capability to sense what its customers are doing in the greater parts of their lives. The greater parts of their lives which are not directly connected to the firm by customer 'touch points'. A firm can only sense through one of its own touchpoints, like its own store, its own website or its own call centre. Firms find it difficult to know what customers do with their competitors. Firms inherently do not know much about how customers use their services and how other services might complement theirs. Second, these limitations imply a danger because firms find it difficult to fully understand customers; because customers have different umwelts, different self-worlds. Managers of a firm experience the world in different ways to their customers. Even if staff members are also customers they are not all the customers. The managers of firm cannot know the full context of using the services that they provide. So they cannot fully understand all the reasons for using the service and all the reasons for not using its service. This is particularly important for understanding non-customers; the people who choose not to be customers. This leaves firms vulnerable to the umwelts of different business models, which operate on different parts of the same customer journey. A firm with a better, or just different, knowledge of customers' service-needs may decide to expand their service offering by competing with a service that better fits the service-needs of customers

Our last point dealt with competition from firms with business models that focus on adjacent parts of the same customer journey. But there is another opportunity for a more radical disruption, which comes from reconnecting ecosystem pathways. In the case, we saw an example of this in how the Quealth app has access to much more information about customers' lives than a pharmacy or a health insurance firm. The app is able to identify and ask questions of each individual user and it accompanies users wherever they take their phone. This is a completely different umwelt to an insurance firm that limits its relationship to asking the customers to renew a policy once a year. Its umwelt is also completely different to a retailer's, even one with many stores and a very sophisticated loyalty card programme. The data that a personal health app captures could potentially be used to by-pass a retailer or an insurance company. To cut them off from the flow of value like a town that is staved of business when a major roadway is rerouted. As Ramirez notes, business development involves the continual reconfiguration of value creation systems over time (1999).

Conceptualising business ecosystems as pathways of flows of value allows us to see business model disruption in terms of a reconfiguration of these pathways, rather than just a change in a business model. The ecosystem pathways concept can be used to think about the construction of new business ecosystem pathways using 
Shaw DR and Allen TFH (2017) Studying innovation ecosystems using ecology theory Technological Forecasting and Social Change. Special issue on innovation ecosystems.

serially interlinked business models. Ecosystem pathways are independent from their components. The interlinked business models can be any business model that fulfils a role.

"In roadtohealth's case, the business model of free distribution through the worlds' largest technology companies such as Samsung, Lenovo and Apple, linked to a healthcoach using the latest AI and speech synthesis modelling, means that preventative healthcare is now available to the mass market on an individual and curated basis" (roadtohealth, 2016b).

We define a 'role' as enabling the recycling of scarce resources at the pathway level, not at the levels of the business model or the firm. The type of business model does not matter. What matters is what it does rather than how it does it. The pathways are characterised by the recycling flows that they convey not the firms or even the types of business models that enable the flows. roadtohealth's role is to help to distribute and recycle health information between ecosystem stakeholders.

"The key success factor appears to be the analysis of multiple layers of data and the 'translation' into language which means something to the consumer" (roadtohealth, 2016b).

The lack of dependence on specific firms or specific business models supports innovation because it allows the recombination of different firms and business models to create emergent business phenomena.

\subsection{Recycling scarce resources is what defines an ecosystem, its development and its health}

Our conceptualisation of ecosystem pathways is consistent with the concept of a value flow system. Resources do flow in a value flow system. But something is conveyed that is in addition to material or informational resources (Shaw, 2007). The value creation systems literature shows us that this additional something is value (Priem, 2007; Moller and Svahn, 2006; Lepak et al., 2007). In the case, the firms functioned according to their business models in a pathway to recycle scarce resources between them. It seems that the scarcest resource is not the customer data because data can easily be reused and shared. The scarcest resource is the customer relationship and the customer's attention. This is less surprising when we think of the effort that firms devote to competing for customers. Any single piece of customer data itself is only of secondary importance to the customer relationship that produces it and the customer attention that initiated it. More important is the permission to use the data; a return channel for reselling the data services that the data produces, back to the customer; and the contextual knowledge of the service-needs of the customer that is enabled by a long term relationships. It is the knowledge and insight that flows between ecosystem firms not so much the raw data of users' answers to the app's actual questions. Knowledge and insight which provides context to turn raw data into information by informing choices. In our innovation ecosystem, the flows were the different aggregations of user data; the different combinations of customer data and other data; and the various inferences that were used to produce data services.

We noticed that the case ecosystem had very few recycling pathways. There was little reuse of customer-based information compared to the potential uses that could be made of it by new partners. This seems to be an indication of the immaturity of the health app ecosystem and potential for adding new partners and new uses of information derived from users. It is the efficient reuse and storage of scarce resources that makes natural ecosystems significant entities. For example, the average time that a nitrogen atom resides in a forest is 1,800 years because most ecosystems are starved of usable nitrogen. It is difficult to compare natural and innovation ecosystems so we compare current reuse to the vast potential reuse of information in this manmade ecosystem. In value co-creation systems all stakeholders are customers as well as suppliers (Ramirez, 1999). So one particular type of reuse of information is in generating contextual knowledge about the customer. Contextual knowledge requires adding together many pieces of information to produce historical trends. This is useful because cause and effect relationships require process data (Markus and Robey, 1988).

The case shows one barrier to developing more information reuse pathways. We can see from how firms use the information in the case that they use it very specifically. Information is specific by its very nature; so specific information is required for use with specific mathematical algorithms so as to generate specifics insights. But how can an information owner, like roadtohealth, know which firms need which information? Especially when these uses of information are novel. The specificity of information use is a barrier to information sharing because information reuse requires a mating of a service, the information, with the specific service-need. This is more like a dating agency, or an ebay-type business model. Rather than an open data repository, which just advertises what data it holds and neglects to show the uses.

A final aspect of recycling customer relationships in the case is how initial customer attention became a customer relationship and the how initial relationship then became tightly recirculated and more focused on the app than on the website or on Google. The initial partners that deal with the user have relatively few, or less frequent, customer interactions than the app. The app produces a service for the user which in turn stimulates the 
Shaw DR and Allen TFH (2017) Studying innovation ecosystems using ecology theory Technological Forecasting and Social Change. Special issue on innovation ecosystems.

user to give the app more data in a positive feedback effect. This positive feedback effect may be the basis of the persistence and growth of the phenomenon of the customer relationship. In turn, these feedback loops are the basis of the pathways which constitute the innovation ecosystem itself.

In fact, the organising principle of an ecosystem is the recycling of scare resources. The significant characteristic of ecosystems is that they sustain themselves in conditions of scarce resources by recycling. But in order for the pathways to recycle scarce resources they must be circular, i.e. they must function as a complete entity. So we emphasise a top-down view. Supply chains are different to pathways because they are not inherently circular and they are not used primarily for scarce resources (Mentzer et al., 2001; Lambert et al., 1998). Collectively recycling scarce resources enables groups of firms to do things that other firms with less access to these resources cannot do, i.e. it enables them to innovate. So our contribution is more than just reusing the ecosystem pathway idea from biology. We have applied it to a new domain and we have also used it to theorise how to build or reengineer an ecosystem; and how to check the health of an ecosystem. Also, recycling resources produces a relative abundance in situations of scarcity. Which is an enabler for innovation.

\subsection{Studying the process of change in a community and in a biome}

In our case, the community perspective and the biome perspective are particularly useful lenses for studying the process of change in different aspects of an innovation ecosystem. The community perspective helps us to study snapshots of evolving processes of accommodation, interspecies competition and mutuality. We can see how business models may lead firms to initially attack each other but then over time they may reach an accommodation. One accommodation is in the way that they change to differentiate their services to reduce competition and even mutually benefit each other. An example of this is when firms specialise in different aspects of a customer journey so as to provide a more complete set of services across a user's whole life. This is a faster and less fundamental change then when a start-up 'pivots' to radically change its business model. Instead, accommodation in the case firms left the business models fundamentally unchanged whilst reconfiguring the service offering and the services themselves. Studies of natural communities look at how organisms of different species integrate and how this integration changes as different species are introduced, or leave the communities in question. Inter-species accommodation may present another conceptual lens for studying the process of market entry for disruptive business models and how this unfolds. We can use the lens of the integration process to investigate this. Also, intra-species accommodation may suggest new methods of studying the line between competition and cooperation that has been referred to as 'coopertition' (Brandenburger and Nalebuff, 1996).

Communities show themselves in interference patterns between the umwelts of component species. Interference patterns are easy to in see nature when they show themselves as checkerboard-like patterns of habitation and nothabitation across the land, or population fluctuations over time. In innovation ecosystems, especially undeveloped ones, they are less easy to perceive. The difficulty of visualising the whole of the World Wide Web makes this problem worse. But it may be that more mature innovation ecosystems display reoccurring variations, in financial success or in market share. As their business models vary in applicability across different market segments and across time; as needs and tastes change.

Umwelts are a self-world not a 'world-view', they include context and capabilities not just sensory input. Umwelts can complement each other from the perspective of a partner firm receiving assistance. But from the perspective of a firm or a researcher trying to understand a market or another ecosystem they can also interfere with each other. For example, shoppers' awareness of stores to shop from and their work commuting journeys interfere to make it difficult for retailers to decide where to locate new stores. Firms should be aware of the possible influence of other umwelts on customers and other firms. Umwelt interference is different to the value gained from using the complimentary umwelts of ecosystem partners. So our contribution is more than just reusing the umwelt concept and the disruptive innovation concept. We have applied them to a new domain and a new organisational level, the ecosystem level. But we have also theorised how firms can avoid or implement disruptive innovation. And we have theorised how disruptive innovation occurs when the lack of an overlap between the umwelts of a firm and its customers means that the firm fails to understand how its customers' needs are changing.

The biome perspective helps us to focus on the process of change in our case's regulatory biome. It helps us to see how cultural and regulatory climates in specific locations influence the success of different business models. And these climates are in turn being influenced by public attitudes. In the case of the regulatory climate we can see how these influences interact in a continuing process of change. Also, this perspective helped us to see how the interrelationships between public attitudes to the uses of new technology drive this sort of climate change in different ways for different scales of biome. We briefly looked at regulatory and cultural acceptance as different innovation climates and we suggest that there are many more influences that are bound to a particular 
Shaw DR and Allen TFH (2017) Studying innovation ecosystems using ecology theory Technological Forecasting and Social Change. Special issue on innovation ecosystems.

geographical area than these two. But as climates they are not a direct aspect of their location; so they can be influenced.

\section{Conclusions}

We propose a set of perspectives for studying innovation ecosystems that are based on a mapping between ecological systems and systems of businesses. Our mapping is based on analogous links in the fundamental natures of the two types of systems, not just their superficial similarity. We do not say that these two types of systems are similar at all levels; just that the similarities continue downwards enough to be useful. From our perspective we think of business model descriptions as similar to the instructions coded in the genome of an organism. Business models interlink to form pathways that convey value in a similar way to the nutrient and energy pathways in a natural ecosystem. These and other ecologically-based perspectives can be used to gain novel insights into how innovation ecosystems function; how they develop; how they can be developed; and how 'healthy' they are functioning. These perspectives can also be used as new ways to study interactions between firms with similar business models; or between firms with different business models. Our use of the business models umwelt concept has highlighted why firms should share data. We have also highlighted several other perspectives that involve the geography that business models operate in and how they interact with the regulatory and cultural climates that they operate in.

\subsection{Contributions for researchers}

Innovation ecosystems is a developing area of the literature and this study contributes to it in four ways.

First, we take the concept of ecosystem pathways and conceptualise these pathways as serially interlinked business models, which recycle scarce resources. This differentiates them from supply chains which are not inherently circular and are not used primarily for scarce resources. Collectively recycling scarce resources enables innovation by concentrating resources and by recombining firms' capabilities. Our contribution is more than just reusing the ecosystem pathway idea from biology. We have also used it to theorise how to build or reengineer an ecosystem; and how to check the health of an ecosystem by checking the health of its pathways.

Second, we take the concept of 'umwelt'; the self-world and apply it to firms. We explain how umwelts limit how well firms understanding their customers, and how this could explain Christensen's concept of disruptive innovation (1997). Accessing others' umwelts gives insight not just sight, which is just sensory data. We also explain how the umwelts of a firm, its customers and its partner firms complement each other but also interfere with each other. So our contribution is more than just reusing the umwelt concept and the disruptive innovation concept. We have also applied them to a new domain and a new organisational level, the ecosystem level.

These two contributions theorise the 'what' of innovation on the ecosystem level of pathways, and 'how' and 'why' it works on the firm level of umwelts. Our theorisation of innovation ecosystems develops the literature on business ecosystems and innovation ecosystems by conceptualising them as being constructed from pathways. The pathways are themselves constructed from serially interlinked business models. The interlinked business models can be any business model that fulfils a role. The role is defined as recycling scarce resources at the pathway level, not at the levels of the business model or the firm. Our theorisation connects ecosystem level behaviour with the business model level.

Third, we extend the innovation ecosystems literature to show its more fundamental mappings to natural ecosystems by illustrating and conceptualising how business models and firms accommodate each other in the case community. Fourth, our study links the literature to the Value Creation literature with its useful concept of subjectivity.

\subsection{Contributions for managers}

This study provides a processual lens for conceptualising innovation ecosystems as roles that are independent of any single firm or any single type of business model. Managers can use this twofold independence to swap in or swap out firms and business models; whilst maintaining a desired ecosystem function. This connection between ecosystem level behaviour and the business models that constitute it makes it useful for ecosystem building, ecosystem reengineering and ecosystem health checks. Also, the six perspectives in our lens are scale independent because they are based on ecology perspectives. In ecology ecosystems, organisms, populations, communities, landscapes and biomes can be small scale or very large scale. Thus our perspectives can be used by managers with job roles that encompass small start-up firms, markets or customer segments, to very large multi-nationals, cities or international economies. Ecosystem ideas can be used innovate at any level and in any job role.

\subsection{Limitations and Future Research}


Shaw DR and Allen TFH (2017) Studying innovation ecosystems using ecology theory Technological Forecasting and Social Change. Special issue on innovation ecosystems.

A single case reduces the possibility of generalisation (Lee, 1989), but we have used it to highlight some gaps in this new area of the literature and to begin to fill them (Siggelkow, 2007). The value flow pathways of our case ecosystem are underdeveloped and simple compared to those in natural ecosystems. This may obscure phenomena that are only observable in their more mature future states. But their simplicity makes exemplars clearer to see and their underdevelopment makes the potential for innovation more evident. These limitations point to areas for future research which also include investigations of data ecosystems with non-health related themes; of how ecosystems appear when the focus is another business model role rather than an app firm, e.g. a role that is far from the retail side; and of the apparent underdevelopment of innovation ecosystem compared to their much older natural counterparts.

\section{Acknowledgements}

We would like to thank roadtohealth group and especially Alistair Wickens, Group Chief Executive; Paul Nash, Clinical Lead, Heather Lane, Head of Finance and Governance, and Nigel Ingham, Director of Innovation for the information that they have provided and for reviewing this paper. We would also like to thank Penelope Siebert and Anurag Kumar.

\section{References}

Allen TFH, Tainter JA, Allen PC, Malek AM, Flynn J and Flynn M (2009) Confronting economic profit with hierarchy theory: The concept of gain in ecology. Systems Research and Behavioral Science 26(5), 583-99.

Allen TFH and Hoekstra TW (2015) Toward a Unified Ecology, second edition, New York; Columbia University Press.

Allen TFH, Shaw D, Allen PC and Spohrer J (2013) Insights into the relationship between products and services coming from biology, Systems Research and Behavioral Science 30:570-79.

Bélanger F and Crossler RE (2011) Privacy in the digital age: a review of information privacy research in information systems, MIS Quarterly, 35 (4) 1017-1041.

Bell K (2014) Samsung's health ambitions go way beyond wearables, Mashabelhttp://mashable.com/2014/11/16/samsung-health-strategy/\#S3n4ElcPSZqJ.

Benbasat I, Goldstein DK and Mead M (1987) The case research strategy in studies of information systems, MIS Quarterly, 11 (3), 369-386.

Brandenburger A and Nalebuff B (1996) Co-opetition: a revolution mindset that combines competition and cooperation, Doubleday Business.

Chalmers M (2004) Hermeneutics, information and representation, European Journal of Information Systems, 13 (3), 210-220.

Checkland P (1999) Systems Thinking, Systems Practice, Chichester: John Wiley \& Sons.

Chesbrough H (2010) Business model innovation: opportunities and barriers, Long Range Planning, 43(2---3), 354-363.

Chourabi H et al. (2012) Understanding smart cities: An integrative framework, (HICSS), 45th Hawaii International Conference on System Science,IEEE.

Christensen, CM (1997) The innovator's dilemma: when new technologies cause great firms to fail, Boston, Massachusetts, USA: Harvard Business School Press.

Clarysse B, Wright M, Bruneel J and Mahajan A (2014) Creating value in ecosystems: Crossing the chasm between knowledge and business ecosystems, Research Policy, 43 (7), 1164-1176.

CMA (2015) Call for information: The commercial use of consumer data, Competition and Markets Authority, www.gov.uk/government/uploads/system/uploads/attachment_data/file/398283/Consumer_Data_-_CFI.pdf.

Dinev T (2014) Why would we care about privacy?, European Journal of Information Systems, 23, 97-102.

Economist (20140 The language of the internet of things, The Economist,

http://www.economist.com/node/21615067/print.

econsultancy (2015) Customer Experience Optimization Report, econsultancy, https://econsultancy.com/reports/customer-experience-optimization.

Eisenhardt M (1989) Building theories from case study research, Academy of Management Review, 14 (4), 532 550. 
Shaw DR and Allen TFH (2017) Studying innovation ecosystems using ecology theory Technological Forecasting and Social Change. Special issue on innovation ecosystems.

Favaro K and Nair R (2015) The Quantified Self Goes Corporate: How to make data your source of sustained growth, strategy+business, 78, spring.

Flint DJ, Lusch RF and Vargo SL (2014), The supply chain management of shopper marketing as viewed through a service ecosystem lens, International Journal of Physical Distribution \& Logistics Management, 44(1/2), 23-38.

Google Play (2015) Google, https://play.google.com/store/apps/details?id=com.roadtohealth.qscore\&hl=en_GB

Hedman, J. and Kalling, T. (2003) The business model concept: theoretical underpinnings and empirical illustrations, European Journal of Information Systems, 12, 49-59.

Hughes TP (1983). Networks of power: Electrification in western society, USA: The Johns Hopkins University Press.

Iansiti M and Levien R (2004a) The Keystone advantage: What the new dynamics of business ecosystems mean for strategy, innovation, and sustainability, Harvard Business School Press, Cambridge, Massachusetts.

Iansiti M and Levien R (2004b) Strategy as ecology, Harvard Business Review, March, 68-78.

Iansiti M and Richards GL (2006) The information technology ecosystem: Structure, health, and performance, The Antitrust Bulletin: 51 (1): 77.

ICO (2014) Big data and data protection, Information Commissioner's Office, https://ico.org.uk/media/fororganisations/documents/1541/big-data-and-data-protection.pdf.

Klein HK, and Myers MD (1999) A Set of Principles for Conducting and Evaluating Interpretive Field Studies in Information Systems, MIS Quarterly, 23 (1), 67-93.

Lambert, D.M., Cooper, M.C. and Pagh, J.D. 1998. "Supply Chain Management: Implementation issues and research opportunities.” International Journal of Logistics Management, 9 (2): 1-19.

Lee AS (1989) A scientific methodology for MIS case studies, MIS Quarterly, 13 (1), 33-50.

Lepak DP, Smith KG and Taylor MS (2007) Value Creation and Value Capture: A Multilevel Perspective, Academy Of Management Review, 32 (1), 180-194.

Lewis H and Liao C (2014) Data Nation: Putting customers first, Deloitte,

http://www2.deloitte.com/content/dam/Deloitte/uk/Documents/deloitte-analytics/deloitte-uk-data-nation2014.pdf.

London Economics (2013) Implications of the European Commission's proposal for a general data protection regulation for business: Final report to the Information Commissioner's Office, https://ico.org.uk/media/aboutthe-ico/documents/1042341/implications-european-commissions-proposal-general-data-protection-regulationfor-business.pdf.

Lotka, AJ (1956) Elements of Mathematical Biology, New York: Dover.

Manyika J, Chui M, Bisson P, Woetzel J, Dobbs R, Bughin J and Aharon D (2015) The Internet of Things: mapping the value beyond the hype, McKinsey Global Institute, June,

http://www.mckinsey.com/insights/business_technology/the_internet_of_things_the_value_of_digitizing_the_p hysical_world.

Markus ML and Robey D (1988) Information Technology and Organizational Change: Causal Structure in Theory and Research, Management Science, 34 (5), 583-598.

Mentzer, J.T., DeWitt, W. and Keebler, J.S. 2001. "Defining supply chain management." Journal of Business Logistics 22 (2): 1-25.

Miller JG (1978) Living Systems: New York.

Moller K and Svahn S (2006) Role of Knowledge in Value Creation in Business Nets, Journal of Management Studies, 43 (5), 985-1007.

Moore JF (1993) Predators and Prey: The New Ecology of Competition, Harvard Business Review, 71(3), 7583.

Moore JF (1996) The Death of Competition: Leadership \& Strategy in the Age of Business Ecosystems, New York: Harper Business. 
Shaw DR and Allen TFH (2017) Studying innovation ecosystems using ecology theory Technological Forecasting and Social Change. Special issue on innovation ecosystems.

Nambisan S and Baron RA (2013) Entrepreneurship in innovation ecosystems: entrepreneurs' self-regulatory processes and their implications for new venture success, Entrepreneurship Theory and Practice, 37 (5), 10711097.

Osterwalder, A., Pigneur, Y. and Tucci, C. L. (2005) Clarifying Business Models: Origins, Present, And Future Of The Concept, Communications of the AIS, 16 (1).

Parliament (2015), UK Parliament website, http://www.parliament.uk/about/how/role/europe/

Patient (2013) How MyHealth can put you on the path to better health, http://patient.info/blogs/georgeford/2013/02/how-myhealth-can-put-you-on-the-path-to-better-healthPatient (2015a) About us, http://patient.info/about-us.

Patient (2015a) New, free online tool set to transform the health of the nation, http://patient.info/pressreleases/new-free-online-tool-set-to-transform-the-health-of-the-nation, accessed 27.11.15.

Patient (2015b) Patient wins big at leading digital awards, Pres release, 12 June 2015, http://patient.info/pressreleases/patient-wins-big-at-leading-digital-awards, accessed 27.11.15.

Patient (2015c) MyHealth registration page, https://myhealth.patient.info/, accessed 27.11.15

Porter ME and Heppelmann JE (2014) How Smart, Connected Products Are Transforming Competition, Harvard Business Review, November 2014.

Porter ME and Heppelmann JE (2015) How Smart, Connected Products Are Transforming Companies, Harvard Business Review, October 2015.

Priem RL (2007) A Consumer Perspective on Value Creation, The Academy of Management Review, 32 (1), 219-235.

Ramirez R (1999) Value co-production: intellectual origins and implications for practice and research, Strategic Management Journal, 20, 49-65.

roadtohealth (2015a) We're live with Samsung S Health!, April 10, http://roadtohealthgroup.com/news/.

roadtohealth (2015b) Clinical Validation, http://roadtohealthgroup.com/\#clinical-validation.

roadtohealth (2015c) Advertisement for Two Clinical Assistant positions, November 2015.

roadtohealth $(2015 \mathrm{~d})$ roadtohealth website, www.roadtohealth.co.uk

roadtohealth (2015e) roadtohealth website, http://roadtohealthgroup.com/\#recognition

roadtohealth (2015f) roadtohealth website, http://roadtohealthgroup.com/\#clinical-validation

roadtohealth (2015g) roadtohealth website, http://www.quealth.co/healthierworld.html

roadtohealth, (2016a) Personal communication with Head of Clinical Governance to validate an earlier version of this paper.

roadtohealth, (2016b) Personal communication with CEO to validate an earlier version of this paper.

Robson C (2002) Real World Research, Oxford: Blackwell, 2nd ed.

Shankar V, Inman JJ, Mantrala M, Kelley E, Rizley R (2011) Innovations in shopper marketing: current insights and future research issues, Journal of Retailing, 1, 29-42.

Shaw DR (2007) Manchester United Football Club: developing a Network Orchestration Model, European Journal of Information Systems, 16 (5), 628-642.

Siggelkow N (2007) Persuasion with case studies. Academy of Management Journal 50 (1), 20-24.

Smith D (2015a) Three years on ... .... and still waiting for reform, Information Commissioner's Office, https://iconewsblog.wordpress.com/2015/02/06/three-years-on-and-still-waiting-for-reform.

Smith D (2015b) The US Safe Harbor - breached but perhaps not destroyed!, Information Commissioner's Office, https://iconewsblog.wordpress.com/2015/10/27/the-us-safe-harbor-breached-but-perhaps-not-destroyed.

Suddaby R (2006) What grounded theory is not. Academy of Management Journal 49 (4), 633-642.

Tansley AG (1935) The use and abuse of vegetational terms and concepts, Ecology, 16(3), 284-307.

TerraCycle (2015) About us, http://www.terracycle.co.uk/en-UK/pages/about-us.html. 
Shaw DR and Allen TFH (2017) Studying innovation ecosystems using ecology theory Technological Forecasting and Social Change. Special issue on innovation ecosystems.

Twitter (2015) Quealth Twitterfeed on November 23, https://twitter.com/Quealth

Uber (2015) Company website, https://get.uber.com/cl/uk/.

Uexküll, J von (1957), A stroll through the worlds of animals and men: A picture book of invisible worlds, In Schiller, $\mathrm{CH}$, Instinctive Behavior: The development of a modern concept. New York: International Universities Press.

UoMassA (2015) What is GeckSkin ${ }^{\mathrm{TM}}$, https://geckskin.umass.edu/

UPS (2005) Demystifying RFID in the Supply Chain: An Overview of the Promise and Pitfalls, www.upsscs.com/solutions/white_papers/wp_RFID.pdf.

Zahra SA and Nambisan S (2012) Entrepreneurship and strategic thinking in business ecosystems, Business Horizons 55, 219-229.

Yin RK (2003) Case Study Research: Design and Methods, Third Edition, Applied Social Research Series, Volume 5, Sage. 